\title{
TAGUCHI- GREY RELATION BASED MULTI-RESPONSE OPTIMIZATION OF DIESEL ENGINE OPERATING PARAMETERS WITH WATER-IN-DIESEL EMULSION FUEL
}

\author{
Suresh Vellaiyan ${ }^{1 *}$, Amirthagadeswaran K.S , Dinesh Babu Sivasamy $^{3}$ \\ ${ }^{1}$ Department of Mechanical Engineering, Haramaya Institute of Technology, Haramaya University, \\ P.O. Box 138, Dire Dawa, Ethiopia \\ ${ }^{2}$ Department of Mechanical Engineering, United Institute of Technology, Coimbatore, Tamil Nadu \\ 641020, India \\ ${ }^{3}$ Department of Mechanical Engineering, University of Houston, Seattle, 4726 Calhoun Rd \\ Houston TX 77204-4006, USA
}

(Received: August 2015 / Revised: September 2017 / Accepted: January 2018)

\begin{abstract}
The use of water-in-diesel (W/D) emulsion fuel has the potential to promote better performance with lower emissions in existing diesel engines. The present study aims to analyzes the influence of operating parameters on the overall engine performance and emission characteristics using W/D emulsion fuel and to obtain the optimum level for favorable performance and emission levels. The engine operating parameters were optimized using a Taguchi-grey relation based multi-response optimization tool. Two controlling parameters, namely compression ratio (CR) and percentage of $\mathrm{W} / \mathrm{D}$, were considered as input process parameters. An $\mathrm{L}_{16}$ orthogonal array was used to collect the output responses (performance and emissions) under varying engine load conditions. The signal-to-noise $(\mathrm{S} / \mathrm{N})$ ratio and grey relational analysis were used to analyze the performance and emission parameters. From the results obtained, it is noted that both controlling parameters have a significant effect on the performance and emission levels. The optimum level of performance and emission levels are obtained at a CR of 18 and water concentration of $10 \%$. Moreover, under these optimum conditions, i.e. at $10 \%$ of water concentration, the fuel properties are at par with the standard diesel fuel properties requirement.
\end{abstract}

Keywords: Emulsion fuel properties; Grey relational analysis; Optimization; Taguchi method; Water-in-diesel emulsion

\section{INTRODUCTION}

Air pollution caused by the diesel engines, especially $\mathrm{NO}_{\mathrm{x}}$ emissions, has led to increased interest in eco-friendly diesel fuels owing to efforts to improve environmental and human health. In order to obtain better emission characteristics of diesel engines, there has been considerable efforts to research and development modified fuels. The introduction of water in diesel engine combustion has been preferred since the desired emission characteristics can be achieved without any added cost (Vellaiyan et al., 2014).

The addition of water in the diesel engine combustion zone was initially proposed in order to promote better inter cooling effect for gas engines. In recent years, the inclusion of water in the diesel engine combustion zone has mainly aimed at promoting lower $\mathrm{NO}_{\mathrm{x}}$ emissions.

\footnotetext{
*Corresponding author's email: suresh.vellaiyan@gmail.com, Tel: +251-0905487286, Fax: +251-025-5-53-03-31 Permalink/DOI: https://dx.doi.org/10.14716/ijtech.v9i1.1374
} 
Several methods are available for adding water in the diesel engine combustion zone, such as direct injection of water into the combustion chamber, fumigating the water into the engine intake air and the use of W/D emulsion fuels (Abu-Zaid, 2004). Among these, W/D emulsion fuels have exhibited better emission characteristics without engine modifications. Moreover, W/D emulsion fuels have favorable fuel characteristics, such as large fragmentation, less change in viscosity, and micro-explosion phenomena of the water droplets (Ghojel et al., 2006).

To prepare stable W/D emulsion fuels, surfactants are used in the emulsification process to lower the surface tension between the water and diesel particles. Among the various cationic, anionic, and nonionic surfactants, nonionic surfactants have positive characteristics, such as burning with no soot and the absence of sulfur and nitrogen, as pointed out by Morozumi and Saito. (2010). In addition, Lin and Chen (2008) reported that the high-speed mechanical homogenization emulsification method has an optimal effect over ultrasonic and supersonic vibrations as far as smoke and $\mathrm{NO}_{\mathrm{x}}$ emissions are concerned. Thus, sorbitan monolaurate (a nonionic surfactant of HLB 8.6) and high-speed mechanical agitator (5000 rpm) were employed in the present study.

Several researches have been conducted to study the performance and emission characteristics of W/D emulsion fuels in diesel engines. As far as the performance and emission characteristics are concerned, the reports are inconsistent since analysis of the combustion phenomena is a complex process. Alahmer (2013) and Vellaiyan and Amirthagadeswaran (2015) reported the positive effects of W/D emulsion fuel in terms of combustion and performance parameters, whereas Yang et al. (2013) and Selim and Ghannam (2007) reported some contradictory results. In terms of emission parameters, all researchers recorded consistent improvement in the NOx emissions, whereas conflicting results have been reported in terms of $\mathrm{HC}$ and $\mathrm{CO}$ emissions (Vellaiyan \& Amirthagadeswaran, 2016a). Following the above discussions, there is a need to further closely study the performance and emission parameters in W/D emulsion fuel combustion.

A number of optimization studies with different optimization tools have been performed to achieve better engine performance and emission levels in diesel engines. Among these, many researchers have preferred Taguchi's off-line quality control concept since it provides a competent and organized approach (Vellaiyan \& Amirthagadeswaran, 2016b). In the conventional Taguchi method, only individual responses can be optimized. In order to perform multi-objective optimization, the Taguchi method must be integrated with modern optimization tools (Vellaiyan \& Amirthagadeswaran, 2017). In the present study, the Taguchi method is coupled with GRA since the intricate multiple performance characteristics can be simplified through Taguchi-grey relational analysis.

The use of W/D emulsion fuels in existing diesel engines has been an active field of research in recent decades. Most reports have been based on the measurement of combustion, performance, and emission characteristics. However, very little effort has been dedicated to analyzing the engine operating parameters' influence on the overall engine performance. Hence, the present study is carried out to meet the following objectives: (i) to analyze the influence of diesel engine operating parameters and water concentration on the performance and emissions levels; (ii) to obtain the optimal parametric setting for better output response using Taguchi-grey relational analysis; and (iii) to measure the fuel properties at optimal parametric settings and compare these with the standard diesel fuel requirements

\section{MATERIAL AND METHODS}

\subsection{Material}

In this work, high-speed diesel was used as the continuous phase of the emulsion. Sorbitan monolaurate (HLB: 8.6) was used as the surfactant (Estelle Chemicals (P) Ltd.). Double distilled filtered water was used as the dispersed phase of the emulsion. 


\subsection{Emulsion Fuel Preparation and Stability Analysis}

To prepare the W/D emulsion fuel, the required quantities of water (5\% to $20 \%$ with equal intervals of $5 \%$ ) and surfactant (1\% of total volume) were added continuously inside the fuelmixing chamber, in which the stirrer speed was maintained at $5000 \mathrm{rpm}$. The schematic layout for emulsion fuel preparation is shown in Figure 1. The emulsion stability was analyzed based on emulsion density variation with respect to time. The stability period was determined using a photonic circuit. The light emitting diode circuit and stability measurement set-up is shown in Figures $2 \mathrm{a}$ and $2 \mathrm{~b}$.

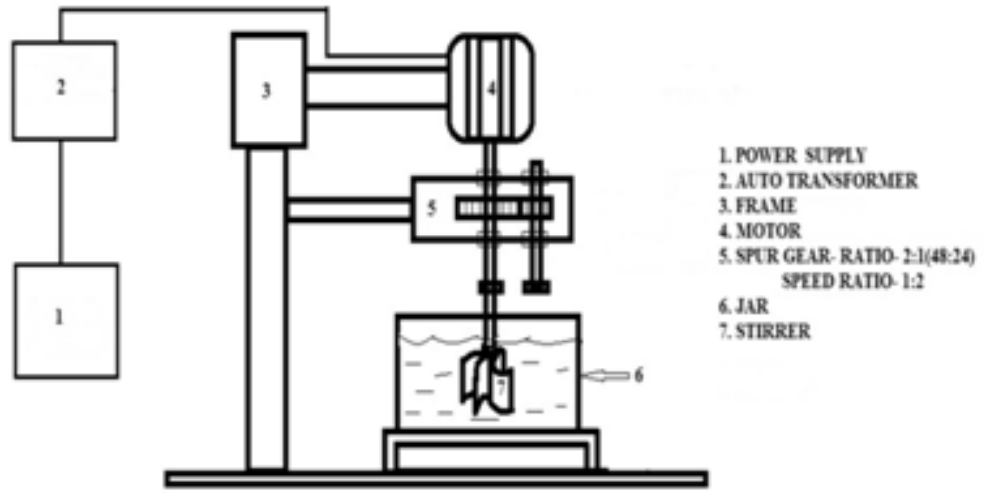

Figure 1 Schematic layout for emulsion fuel preparation

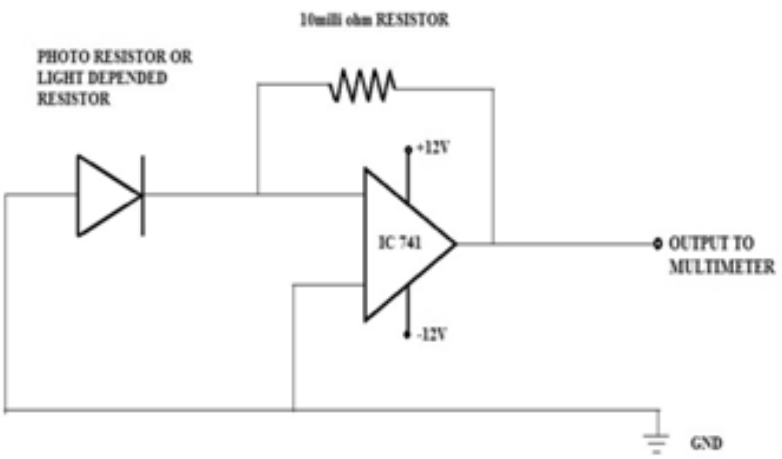

(a)

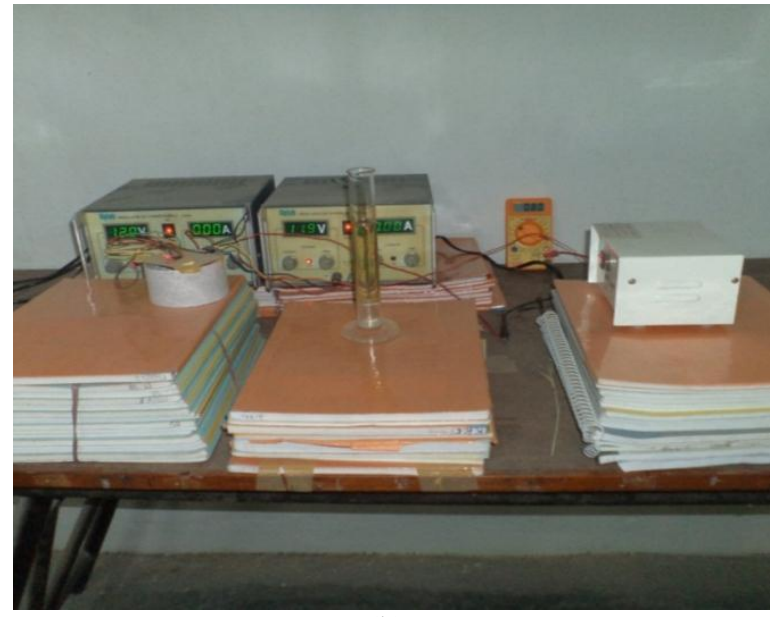

(b)

Figure 2 (a) Light emitting diode circuit; (b) Photograph of stability measurement set-up

\subsection{Engine Test Set-up}

The engine used in the present experiment is a computerized, single cylinder, four stroke, variable compression ratio, naturally aspirated diesel engine with an eddy current dynamometer. The fuel injection timing was kept at 23 degrees BTDC. ICEnginesoft_9.0 software was used to record the combustion and performance parameters. Emission parameters were recorded using AVL digas analyzer. Table 1 presents detailed specifications of the engine and emission analyzer. Figure 3 shows a photograph of the engine test set-up. The experiments were carried out under different loading conditions $(25 \%, 50 \%, 75 \%$, and $100 \%)$ for various CRs $(15,16,17 \& 18)$ and water concentrations $(5 \%, 10 \%, 15 \%$, and $20 \%)$ based on orthogonal array. 
Table 1 Specifications of engine and emission analyzer

\begin{tabular}{|c|c|c|}
\hline \multicolumn{3}{|c|}{ (a) Engine specifications } \\
\hline Parameter & \multicolumn{2}{|c|}{ Specification } \\
\hline Engine type & \multicolumn{2}{|c|}{$\begin{array}{l}\text { Computerized, 4-Stroke, Single cylinder, VCR diesel } \\
\text { engine }\end{array}$} \\
\hline Bore $\times$ Stroke $(\mathrm{m})$ & \multicolumn{2}{|c|}{$0.0875 \times 0.11$} \\
\hline Displacement volume (cc) & \multicolumn{2}{|l|}{661.45} \\
\hline Max. power & \multicolumn{2}{|l|}{$3.5 \mathrm{~kW}$ at $1500 \mathrm{rpm}$} \\
\hline $\mathrm{CR}$ range & \multicolumn{2}{|l|}{$14-18$} \\
\hline Dynamometer & \multicolumn{2}{|c|}{ Eddy current dynamometer $(\max$ load $=7.5 \mathrm{~kW})$} \\
\hline \multicolumn{3}{|c|}{ (b) Gas analyzer specifications } \\
\hline Measured quality & Measuring range & Resolution \\
\hline $\mathrm{NO}_{\mathrm{x}}$ & 0 to 5000 ppm vol. & 1 ppm vol. \\
\hline $\mathrm{HC}$ & 0 to $20000 \mathrm{ppm}$ vol. & $\begin{array}{l}\leq 2000: 1 \mathrm{ppm} \text { vol. } \\
>\text { 2000: } 10 \mathrm{ppm} \text { vol. }\end{array}$ \\
\hline $\mathrm{CO}$ & $0-10 \%$ vol. & $0.01 \%$ vol. \\
\hline $\mathrm{CO}_{2}$ & $0-20 \%$ vol. & $0.1 \%$ vol. \\
\hline
\end{tabular}

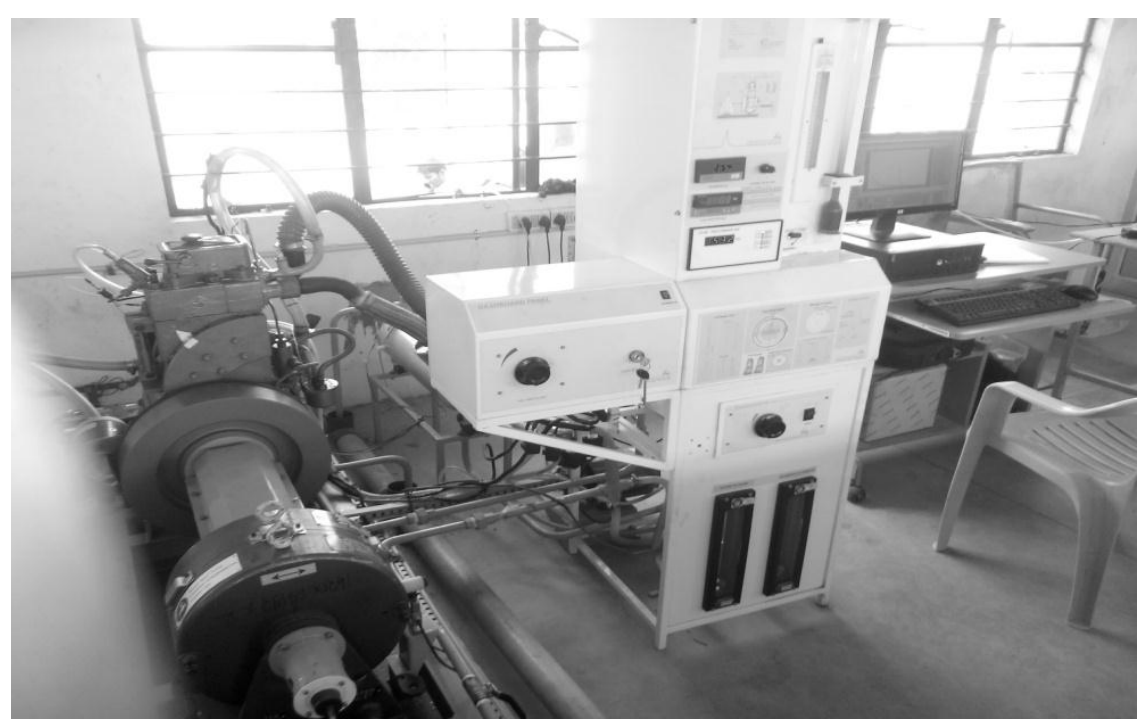

Figure 3 Photograph of engine set-up

\subsection{Experimental Details and Taguchi-grey Analysis}

The present study employs the Taguchi $\mathrm{L}_{16}$ orthogonal array to plan the experiments on the diesel engine. Two controlling factors, (i) $\mathrm{CR}$ and (ii) water concentration in diesel, were identified as the input parameters. Combustion phases, such as SOC, MFB and EOC, are the critical factors affecting the performance and emission characteristics of diesel engines. Both the abovementioned controlling factors have a direct influence on the combustion phases. At high compression ratios, reduction of the maximum pressure increase rate and ignition delay lead to better performance characteristics of diesel engines. A longer ignition delay with low compression ratio results in engine failure (Vellaiyan \& Amirthagadeswaran, 2016c). Hence, the parameter levels for compression ratio were chosen to be 15 to 18 with equal intervals. The parameter levels for water concentration were chosen as $5 \%$ to $20 \%$ of the total volume of fuel with $5 \%$ equal intervals. Addition of water to diesel provides low level of emissions, while increasing water concentration, ignition delay period, and combustion duration (Selim \& Ghannam, 2007). 
The following procedure was adopted to convert a multi-response optimization problem into a single response problem: (1) Experimental data were first normalized ranging from zero to one; (2) The grey relational coefficient was estimated based on the normalized experimental data; and (3) The overall grey relational grade was obtained by averaging the grey relational coefficients corresponding to each selected response (Aydin et al., 2010). The combination of parameters having highest grey relational grade is expected to be closer to the optimal parametric setting. The optimum parametric setting was determined based on the $\mathrm{S} / \mathrm{N}$ ratio.

In the present study, BTE has been characterized as "the larger the better" and is computed as follows:

$$
x_{(i)} k=\frac{y_{i}(k)-\min y_{i}(k)}{\max y_{i}(k)-\min y_{i}(k)}
$$

BSFC and emission parameters have been characterized as "the smaller the better" and are computed as follows:

$$
x_{(i)} k=\frac{\max y_{i}(k)-y_{i}(k)}{\max y_{i}(k)-\min y_{i}(k)}
$$

where $x_{i}(k)$ is the sequence for comparison, $y_{i}(k)$ is the original reference sequence, $\mathrm{I}=1,2, \ldots$. $\mathrm{m}, \mathrm{k}=1,2, \ldots . \mathrm{n}$, and $\mathrm{m}, \mathrm{n}$ are the total number of experiments and response. The values min $\mathrm{y}_{\mathrm{i}}(\mathrm{k})$ and max $y_{i}(k)$ are the smallest and highest values of $y_{i}(k)$, respectively.

The grey relational coefficient $\xi_{\mathrm{i}}(\mathrm{k})$ is calculated as follows:

$$
\begin{aligned}
\xi_{\mathrm{i}}(\mathrm{k})= & \frac{\Delta_{\min }-\psi \Delta_{\max }}{\Delta_{0 \mathrm{i}}(\mathrm{k})+\psi \Delta_{\max }} \\
& \Delta_{0 i}(k)=|| x_{0}(k)-x_{i}(k)||
\end{aligned}
$$

where $\Delta_{0 \mathrm{i}}$ is the value of absolute difference. $\Delta_{\min }$ and $\Delta_{\max }$ are the minimum and maximum values among the absolute differences. The purpose of the distinguishing coefficient $\psi(0 \leq \psi \leq 1)$ is to weaken the effect of $\Delta_{\max }$ when it becomes too large. In the present study, the value of $\psi$ was taken as 0.5 . The grey relational grade $y_{0}$ is calculated as:

$$
y_{0}=\sum_{k=1}^{n} \xi_{i}(k) \beta y_{i} \ldots, \quad \sum \beta=1
$$

where $\beta$ is the weighing factor. While converting the multiple grey relation grades, equal weightages were assigned for the performance and emission characteristics. The following values of weightage were adopted for different responses: BSFC 0.25, BTE 0.25, $\mathrm{HC} 0.2, \mathrm{NO}_{\mathrm{x}} 0.2, \mathrm{CO}$ 0.05, and $\mathrm{CO}_{2}$ 0.05. Among the four emission parameters, $\mathrm{CO}$ and $\mathrm{CO}_{2}$ were assigned lower values since the diesel engine burns a lean mixture, which produces a low level of CO. To optimize the process parameters, the experimental data were normalized to obtain the grey relational grade. The $\mathrm{S} / \mathrm{N}$ ratio for the overall grey relational grade is found from the following equation:

$$
\mathrm{S} / \mathrm{N}=-10 \log \frac{1}{n} \sum_{i=1}^{n} \frac{1}{y_{i}^{2}}
$$


where $i=1,2, \ldots n$, and $y_{i}$ is the response value for an experimental condition.

\section{RESULTS AND DISCUSSION}

Based on the $\mathrm{L}_{16}$ orthogonal array, sixteen experiments were conducted under varying load conditions $(25 \%, 50 \%, 75 \%$, and $100 \%$ load). Table 2 shows the grey relational grade for experimental data under varying load conditions and its order. It can be observed that CR-18 with $10 \%$ of water concentration in diesel provides high grey relational grade under $50 \%, 75 \%$, and $100 \%$ load conditions, whereas $5 \%$ water concentration in diesel promotes high grey relational grade under $25 \%$ load condition. It also noted that the lower compression ratio along with W/D emulsion fuel leads to poor performance and emissions levels throughout the experiments. This may be due to the longer ignition delay period and the lower combustible charge temperature. Increases in CR improve the performance and emissions level in the case of the emulsion fuel.

Table 2 Grey relational grade for different loading conditions and its order

\begin{tabular}{|c|c|c|c|c|c|c|c|c|c|c|}
\hline \multirow[b]{2}{*}{$\begin{array}{l}\text { Run } \\
\text { No. }\end{array}$} & \multirow[b]{2}{*}{$\mathrm{CR}$} & \multirow[b]{2}{*}{ Blend } & \multicolumn{2}{|c|}{$25 \%$ load } & \multicolumn{2}{|c|}{$50 \%$ load } & \multicolumn{2}{|c|}{$75 \%$ load } & \multicolumn{2}{|c|}{$100 \%$ load } \\
\hline & & & $\begin{array}{c}\text { Grey } \\
\text { Relation } \\
\text { Grade }\end{array}$ & Order & $\begin{array}{c}\text { Grey } \\
\text { Relation } \\
\text { Grade }\end{array}$ & Order & $\begin{array}{c}\text { Grey } \\
\text { Relation } \\
\text { Grade }\end{array}$ & Order & $\begin{array}{c}\text { Grey } \\
\text { Relation } \\
\text { Grade }\end{array}$ & Order \\
\hline 1 & 15 & 5 & 0.492888 & 11 & 0.546603 & 14 & 0.597877 & 15 & 0.604344 & 16 \\
\hline 2 & 15 & 10 & 0.509378 & 6 & 0.592591 & 6 & 0.665321 & 6 & 0.701166 & 6 \\
\hline 3 & 15 & 15 & 0.520810 & 2 & 0.591228 & 7 & 0.626375 & 11 & 0.633044 & 14 \\
\hline 4 & 15 & 20 & 0.506239 & 7 & 0.577638 & 9 & 0.623574 & 12 & 0.700744 & 7 \\
\hline 5 & 16 & 5 & 0.480966 & 14 & 0.563817 & 13 & 0.623381 & 13 & 0.644539 & 13 \\
\hline 6 & 16 & 10 & 0.483480 & 13 & 0.568160 & 11 & 0.627792 & 10 & 0.674393 & 10 \\
\hline 7 & 16 & 15 & 0.491295 & 12 & 0.564966 & 12 & 0.639753 & 9 & 0.654838 & 12 \\
\hline 8 & 16 & 20 & 0.460142 & 16 & 0.526176 & 16 & 0.571117 & 16 & 0.626718 & 15 \\
\hline 9 & 17 & 5 & 0.506193 & 8 & 0.577613 & 10 & 0.664055 & 8 & 0.681298 & 9 \\
\hline 10 & 17 & 10 & 0.512689 & 5 & 0.603580 & 5 & 0.676162 & 5 & 0.716593 & 4 \\
\hline 11 & 17 & 15 & 0.499890 & 10 & 0.583017 & 8 & 0.664077 & 7 & 0.691142 & 8 \\
\hline 12 & 17 & 20 & 0.474729 & 15 & 0.540510 & 15 & 0.606893 & 14 & 0.666518 & 11 \\
\hline 13 & 18 & 5 & 0.521817 & 1 & 0.622180 & 2 & 0.684178 & 2 & 0.759383 & 2 \\
\hline 14 & 18 & 10 & 0.517801 & 3 & 0.644840 & 1 & 0.733170 & 1 & 0.816048 & 1 \\
\hline 15 & 18 & 15 & 0.503311 & 9 & 0.612736 & 3 & 0.681450 & 3 & 0.747301 & 3 \\
\hline 16 & 18 & 20 & 0.512718 & 4 & 0.609911 & 4 & 0.677962 & 4 & 0.714110 & 5 \\
\hline
\end{tabular}

Table 3 shows the responses of the grey relational grade for all loading conditions. The results revealed that both the factors have significant influence on the output responses. The variation percentages of the effects are between $5 \%$ and $15 \%$ under all loading conditions. However, CR clearly plays a vital role on the overall engine performance in the domain of W/D emulsion fuels. The delta value also increased with increase in load.

$\mathrm{S} / \mathrm{N}$ ratio graph for all loading conditions are shown in Figures $4 \mathrm{a}-4 \mathrm{~d}$. From the graph, it is noted that $10 \%$ of water concentration in diesel at $\mathrm{CR}$ of 18 provides high $\mathrm{S} / \mathrm{N}$ ratio value for all loading conditions. It is also noted that W/D emulsion fueled diesel engines running at 16-CR exhibits poor performance and emissions level when compared to other setting parameters. An increase in load increases the $\mathrm{S} / \mathrm{N}$ ratio throughout the experiments. Table 4 shows the optimum level of engine operating parameters for varying load conditions. Based on the results, it can be concluded that the optimum combination for better performance and lower emissions for all loading conditions is CR 18 with $10 \%$ of water concentration in diesel. 
Table 3 Response table for the grey relational grade

\begin{tabular}{ccccccc}
\hline S.No & Engine Operating Parameters & Level 1 & Level 2 & Level 3 & Level 4 & Delta \\
\hline \multicolumn{7}{c}{$25 \%$ load } \\
1 & CR & 0.5073 & 0.4790 & 0.4984 & 0.5139 & 0.0349 \\
2 & Blend & 0.5005 & 0.5058 & 0.5038 & 0.4885 & 0.0174 \\
\hline \multicolumn{7}{c}{$50 \%$ load } \\
1 & CR & 0.5770 & 0.5558 & 0.5762 & 0.6224 & 0.0666 \\
2 & Blend & 0.5776 & 0.6023 & 0.5880 & 0.5636 & 0.0387 \\
\hline \multicolumn{7}{c}{$75 \%$ load } \\
1 & CR & 0.6283 & 0.6155 & 0.6528 & 0.6942 & 0.0787 \\
2 & Blend & 0.6424 & 0.6756 & 0.6529 & 0.6199 & 0.0557 \\
\hline & & $100 \%$ load & & & & \\
1 & CR & 0.6598 & 0.6501 & 0.6889 & 0.7592 & 0.1091 \\
2 & Blend & 0.6724 & 0.7270 & 0.6816 & 0.6770 & 0.0547 \\
\hline
\end{tabular}

Table 4 Optimum level of engine operating parameters for varying load conditions

\begin{tabular}{cccc}
\hline S.No & Load (\%) & CR & Water concentration in diesel (\%) \\
\hline 1 & 25 & 18 & 10 \\
2 & 50 & 18 & 10 \\
3 & 75 & 18 & 10 \\
4 & 100 & 18 & 10 \\
\hline
\end{tabular}

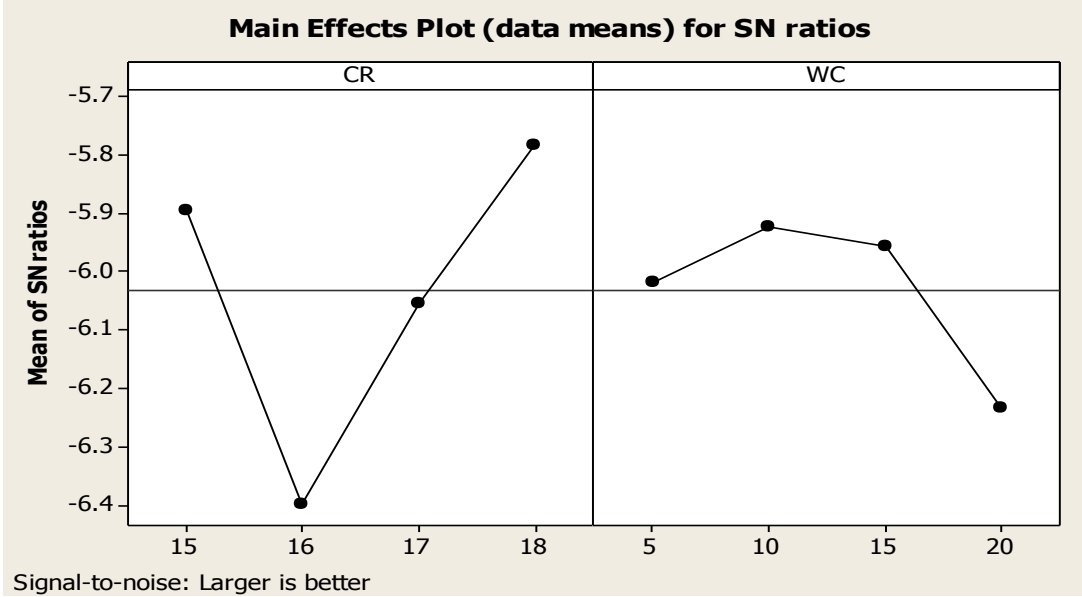

Figure 4 (a) S/N ratio graph for $25 \%$ load

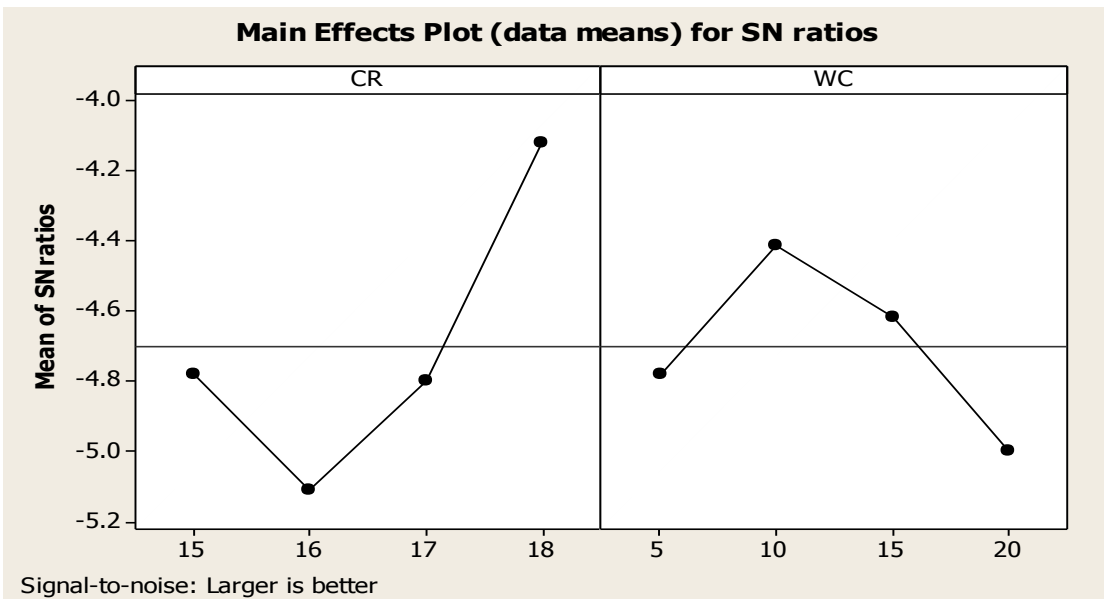

Figure 4 (b) S/N ratio graph for $50 \%$ load 


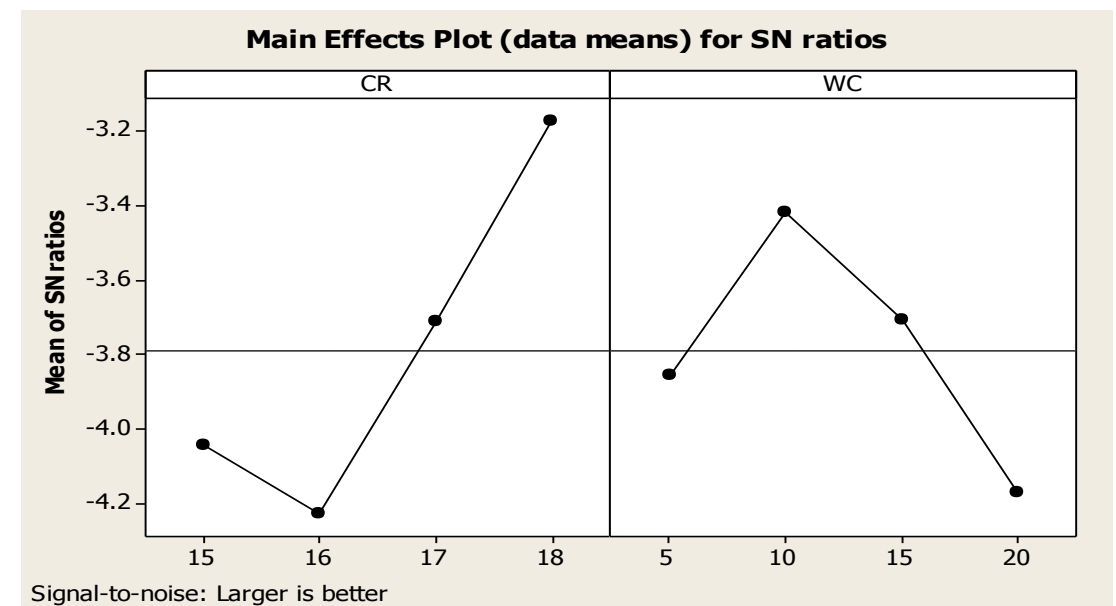

Figure 4 (c) S/N ratio graph for $75 \%$ load

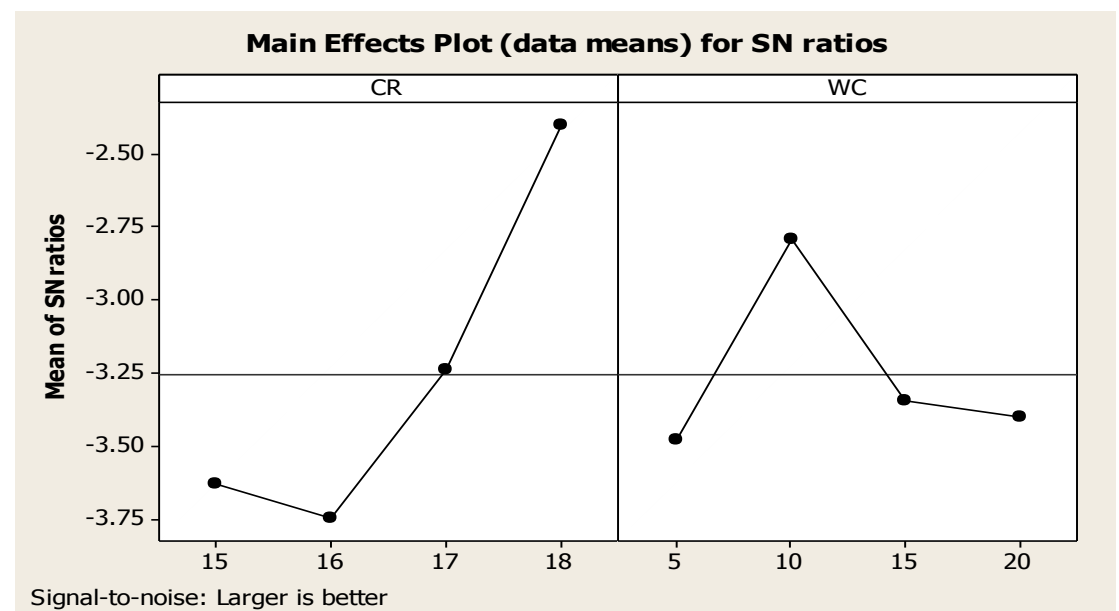

Figure 4 (d) S/N ratio graph for $100 \%$ load

The fuel properties of $\mathrm{BD}$ and 10\% W/D (optimal parametric setting) were measured according to EN 590:2009 and compared with the European standard of automotive diesel fuel requirements (EN 590:2009). The comparisons are presented in Table 5. All the physico-chemical properties are increased with an increase in the water concentration, except the calorific value. This may be due to the endothermic reaction of water particles present in the diesel. However, the physicochemical properties of $10 \% \mathrm{~W} / \mathrm{D}$ emulsion fuel have shown good agreement with standard diesel fuel requirements

Table 5 Physico-chemical properties of BD and 10\% W/D emulsion fuel and its comparison with EN 590:2009 properties

\begin{tabular}{cccccc}
\hline \multirow{2}{*}{ Fuels } & \multicolumn{5}{c}{ Fuel Properties } \\
\cline { 2 - 6 } & $\begin{array}{c}\text { Density } \\
\text { at } 15^{\circ} \mathrm{C} \\
\left(\mathrm{kg} / \mathrm{m}^{3}\right)\end{array}$ & $\begin{array}{c}\text { Viscosity at } 40^{\circ} \mathrm{C} \\
\left(\mathrm{mm}^{2} / \mathrm{s}\right)\end{array}$ & $\begin{array}{c}\text { Flash } \\
\text { point }{ }^{\circ} \mathrm{C}\end{array}$ & $\begin{array}{c}\text { Heating } \\
\text { value } \\
(\mathrm{MJ} / \mathrm{kg})\end{array}$ & $\begin{array}{c}\text { Copper strip } \\
\text { corrosion } \\
\text { resistance }\end{array}$ \\
\hline BD & 831.4 & 2.4 & 62 & 43.8 & Class I \\
10\% of W/D & 845 & 4.4 & 74 & 42.1 & Class I \\
European Standard & $820-845$ & $2-4.5$ & Above 55 & NA & Class I \\
(EN 590:2009) & & & & & \\
\hline
\end{tabular}




\section{CONCLUSION}

In order to analyze the effect of the operating parameters of a diesel engine running on W/D emulsion fuel and to obtain the optimum levels, the Taguchi-grey relation based multi-response optimization tool has been applied and the results presented. Based on the results, it can be concluded that $\mathrm{CR}$ and the concentration of water have a significant effect on the performance and emission characteristics of the diesel engine. The optimal parametric settings to provide better performance and emission characteristics are predicted as CR 18 and $10 \%$ water concentration in diesel for all loading conditions. Further, the measured physico-chemical properties of $10 \%$ W/D emulsion fuel meet the EN 590:2009 fuel standard and thus can be used directly in existing diesel engines.

\section{NOMENCLATURES}

$\begin{array}{llll}\text { BSFE } & \text { Brake specific fuel consumption } & \text { HC } & \text { Hydrocarbon } \\ \text { BTE } & \text { Brake thermal efficiency } & \text { HLB } & \text { Hydrophilic-lipophilic balance } \\ \text { CC } & \text { Combustion chamber } & \text { MFB } & \text { Mass fraction burned } \\ \text { CO } & \text { Carbon monoxide } & \text { NO } & \text { Nitric Oxide } \\ \mathrm{CO}_{2} & \text { Carbon dioxide } & \text { NOx } & \text { Nitrogen Oxides } \\ \text { EOC } & \text { End of combustion } & \text { SOC } & \text { Starting of combustion } \\ \text { GRA } & \text { Grey relational analysis } & \text { W/D } & \text { Water-in-diesel }\end{array}$

\section{REFERENCES}

Abu-Zaid, M., 2004. Performance of Single Cylinder, Direct Injection Diesel Engine using Water Fuel Emulsion. Energy Conversion and Management, Volume 45, pp. 697-705

Alahmer, A., 2013. Influence of using Emulsified Diesel Fuel on the Performance and Pollutants Emitted from Diesel Engine. Energy Conversation and Management, Volume 73, pp. 361369

Aydin, H., Bayram, A., Esme, U., Guven, O., 2010. Application of Grey Relational Analysis (GRA) and Taguchi Method for the Parametric Optimization of Friction Stir Welding (FSW) Process. Materials and Technology, Volume 44, pp. 205-211

Ghojel, J., Honnery, D., Al-Khaleefi, K., 2006. Performance, Emissions and Heat Release Characteristics of Direct Injection Diesel Engine Operating on Diesel Oil Emulsion. Applied Thermal Engineering. Volume 26, pp. 2132-2141

Lin, C.-Y., Chen, L.-W., 2008. Comparison of Fuel Properties and Emission Characteristics of Two- and Three-Phase Emulsions Prepared by Ultrasonically Vibrating and Mechanically Homogenizing Emulsification Methods. Fuel, Volume 87, pp. 2154-2161

Morozumi, Y., Saito, Y., 2010. Effect of Physical Properties on Micro Explosion Occurrence in Water-in-Oil Emulsion Droplets. Energy Fuels, Volume 24, pp. 1854-1859

Selim, M., Ghannam, M., 2007. Performance and Engine Roughness of a Diesel Engine Running on Stabilized Water Diesel Emulsion. SAE Technical Paper 2007-24-0132

Vellaiyan, S., Amirthagadeswaran K.S., 2015. Combustion and Performance Characteristics of Water-in-Diesel Emulsion Fuel. Energy Sources, Part A: Recovery, Utilization, and Environmental Effects, Volume 37, pp. 2020-2028

Vellaiyan, S., Amirthagadeswaran, K.S., 2016a. Influence of Water-in-Diesel Emulsion Fuel and Compression Ratio on Combustion, Performance and Emission Characteristics of Diesel Engine. Journal of Sustainable Energy Engineering, Volume 3, pp. 238-253

Vellaiyan, S., Amirthagadeswaran, K.S., 2016b. Taguchi-Grey Relational Based Multi-response Optimization of Water-in-Diesel Emulsification Process. Journal of Mechanical Science and Technology, Volume 30(3), pp. 1399-1404 
Vellaiyan, S., Amirthagadeswaran, K.S., 2016c. Zinc Oxide Incorporated Water-in-Diesel Emulsion Fuel - Formulation, Particle Size Measurement and Emission Characteristics Assessment. Petroleum Science and Technology, Volume 34(2), pp. 114-122

Vellaiyan, S., Amirthagadeswaran, K.S., 2017. Multi-Response Optimization of Diesel Engine Operating Parameters Running with Water-in-Diesel Emulsion Fuel, Thermal Science, Volume 21(1B), pp. 427-439

Vellaiyan, S., Amirthagadeswaran, K.S., Varun, B., Vijayakumar, S., 2014. Emission Characteristics of Diesel Engine using Water-in-Diesel Emulsified Fuel and its CFD Analysis. International Journal of Applied Environmental Sciences, Volume 9, pp. 27392749

Yang, W.M., An, H., Chou, S.K., 2013. Impact of Emulsion Fuel with Nano-organic Additives on the Performance of Diesel Engine. Applied Energy, Volume 112, pp. 1206-1212 